\title{
Genre studies and archives: introduction to the special issue
}

\author{
Gillian Oliver - Wendy M. Duff
}

Published online: 14 August 2012

(C) Springer Science+Business Media B.V. 2012

Genre can be defined as a pattern of communication that conforms to community norms. Genres are not fixed, but are constantly evolving and emerging. Examples of familiar genres range from speech utterances to publications, from text messages to databases, from blogs to formal reports. Genre studies are a multi-disciplinary area, which has the potential to yield much of relevance to the archival community.

With these words, we introduced our call for the papers for this special issue of Archival Science. We were cautiously optimistic that authors would come forward with interesting and insightful papers on various aspects of genre and archives. We received a tremendous response, with a large number of very promising proposals. The seven papers that subsequently made it through the reviewing process into this special issue represent the highest quality submissions, but by no means the totality of research activity in archival science with a focus on genre.

The concept of genre is not one that has figured prominently in either archival discourse or practice to date. It has been suggested that there is a potential for it to be relevant in archival description and appraisal (Oliver et al. 2008), but it has attracted much more interest in related disciplines-particularly the information retrieval/information seeking behaviour research communities (see Anderson 2008 for an in depth literature review of genre in information studies).

Consequently, if asked about genre, an archivist may think of those ill-conceived lists of document types, which become longer and longer as yet another ambiguous 'type' is added. Or, he or she may think of genre as a blunt instrument used in libraries to organise the fiction collection into broad groupings such as romance, mysteries and

G. Oliver $(\square)$

School of Information Management, Victoria University of Wellington,

Wellington, New Zealand

e-mail: Gillian.oliver@vuw.ac.nz

W. M. Duff

Faculty of Information, University of Toronto, Toronto, Canada

e-mail: wendy.duff@utoronto.ca 
so on. In short, the concept of genre comes with the accompanying baggage of a doubtful reputation. Perhaps one contributing factor is a lack of understanding or lack of interest in the research emerging from the broader genre community.

Though few archivists have discussed their ideas within the framework of genre theory, they have focussed on aspects of the concept. For example, James O'Toole discussed the symbolism of records and perspectives of them as objects that may arouse strong emotions (O'Toole 1993); Robert Hartland and colleagues describe the situation in which we live as a web of documents, in which the environment changes as new technologies emerge, but the web of documents is constant (Hartland et al. 2005).

Genre theory can build on and enrich studies of the document. The genre community in its entirety can be grouped into three distinct sub-fields: English for Specific Purposes, North American/New Rhetorical Studies and Australian Systemic Functional Linguistics (Genre 2012). The sub-field that this special issue draws on is that of New Rhetorical Studies. New Rhetorical Studies can in turn be categorised in two broad groups: traditional and current genre studies. Traditional studies mine the familiar territory that includes literary genres (poetry, drama, prose etc.), but the objects of attention for current studies are non-literary texts; furthermore, current studies seek linkages between discourse and human action (Freedman and Medway 1994). This recognition of context, and exploration of influences that shape and fashion communicative activity, resonates with the archival endeavour and is the focus of this issue.

There is undoubtedly heightened awareness of genre-like issues as recordkeeping practitioners grapple with the challenges presented by emerging digital documentary forms. Deeper reflection, going beyond the merely technical how to questions, may assist in the development of meaningful solutions. For instance, discussing the changing nature of the archive, Kate Eichhorn identifies historical antecedents of new documentary forms, providing a detailed comparison between commonplace books and blogs, as an example. She concludes with the following words that provide a fitting frame for this special issue:

Like the archive, which is neither a neutral space where texts and artifacts simply accumulate nor the source of a single or stable narrative, archival genres may be understood as collections and spaces where readers and writers are permitted to dwell amongst documentary remains, crafting new narratives and new genres (Eichhorn 2008, p. 8).

The opening paper (The orders of documents, the orders of activity, and the orders of information) comes from Charles Bazerman, a foundational and influential thinker in genre studies, who is cited by almost all subsequent contributors to this special issue. He provides a user perspective on archives and documentary forms, arguing that it is necessary for the archival scholars to understand genre-which speaks to our responsibilities as archivists.

It might be argued that diplomatics, the study of documents that first emerged in the eighteenth century, already addresses many aspects of genre theory that has been absent in the discourse of the broader genre community. Fiorella Foscarini's paper argues for the acceptance of genre theory as a complementary approach to 
diplomatics and explores ways in which diplomatics could contribute to genre theory. Her ideas open up exciting and challenging prospects and will hopefully lead to much productive future dialogue.

The following papers all discuss particular genres or genre systems. Steve Wright ('I came like the thunder and I vanish like the wind': exploring genre repertoire and document work in the Assemblea operai e studenti of 1969) provides a compelling account of documents likely to be found in community archives. Pamela McKenzie and Elisabeth Davies' paper (Genre systems and "keeping track" in everyday life) brings the seemingly mundane records of our daily lives into the spotlight with a vivid and readable analysis of the genres used to keep track of daily activities and responsibilities. This paper provides insights into personal recordkeeping.

Hea Lim Rhee takes us back to institutional archives and professional practice in her consideration of the genres of user and use information, utilised as appraisal tools (Genres and genre repertoires of user and use information sources in U.S. state archival and records management appraisal practice). This paper demonstrates the utility of the genre concept, applied to archival practice.

Concluding this special issue are two papers focusing on a genre that is an integral part of archival practice: the finding aid. Heather MacNeil (What finding aids do: archival description as rhetorical genre in traditional and web-based environments) reports on the first stage of a research project conceptualising archival description as rhetorical genre. Her detailed discussion of the conceptual framework of genre studies and its relevance to archival description provides an important contribution that will doubtless underpin much further scholarship in this domain.

Finally, Ciaran Trace and Andrew Dillon (The evolution of the finding aid in the United States: From physical to digital document genre) turn their attention to American finding aids in particular, using genre theory to emphasise the need for archivists to take into account the 'consumption and use' of finding aids by their patrons. This concluding paper brings us back full circle to where we started, with consideration of the user perspective.

The totality of the papers published in this special issue will hopefully motivate further research by archivists, encourage scholars already active in this area as well as suggest new avenues for exploration.

\section{References}

Anderson J (2008) The concept of genre in information studies. Annu Rev Inf Sci Technol 42(1):339-367 Eichhorn K (2008) Archival genres: gathering texts and reading spaces. Invisible culture (12) http://www.rochester.edu/in_visible_culture/Issue_12/eichhorn/eichhorn.pdf. Accessed 2 July 2012

Freedman A, Medway P (1994) Locating genre studies: antecedents and prospects. In: Freedman A, Medway P (eds) Genre and the new rhetoric. Taylor \& Francis, London

Genre (2012) Rethinking genre 20 years later, an international conference on genre studies. http://www3.carleton.ca/genre2012/. Accessed 6 July 2012

Hartland R, McKemmish S, Upward F (2005) Documents. In: McKemmish S, Piggott M, Reed B, Upward F (eds) Archives: recordkeeping in society. Centre for Information Studies, Wagga Wagga, pp 75-100 
O'Toole JM (1993) The symbolic significance of archives. Am Arch 56:234-255

Oliver G, Kim Y, Ross S (2008) Documentary genre and digital recordkeeping: red herring or a way forward? Arch Sci 8:295-305

\section{Author Biographies}

Wendy M. Duff is a professor at the Ischool at the University of Toronto and the Director of the Digital Curation Institute. She is a founding member of AX-SNet, an evolving international team of researchers interested in facilitating access to archival materials. She has also served as a member of the ICA Adhoc Commission on Descriptive Standards, the Encoded Archival Description Working Group and the Canadian Council of Archives Standards Committee. Her current research focuses on archival users, access to archival material, digital curation and the convergence of libraries, archives and museums. One of her collaborative projects investigated the impact of technology on museums for the Canadian Heritage Information Network. Wendy was a visiting professor at Victoria University of Wellington in 2011.

Gillian Oliver is Senior Lecturer in Archives and Records Management at the School of Information Management, Victoria University of Wellington. Her current research focuses on the information culture of organisations, within the contextual framework of recordkeeping informatics. 